\title{
ELABORAÇÃO DE FERMENTADO FRISANTE DE MAÇÃ COM CARACTERÍSTICAS SEMELHANTES À SIDRA FRANCESA
}

\author{
JOSÉ RICARDO FERREIRA DE CARVALHO* \\ KAROLLINE MARQUES DA SILVA** \\ DEISE ROSANA SILVA SIMÕES*** \\ GILVAN WOSIACKI**** \\ ALESSANDRO NOGUEIRA*****
}

\begin{abstract}
Este trabalho teve como objetivo elaborar fermentado frisante de maçã com características de qualidade baseadas na sidra francesa e na preferência do consumidor brasileiro. Utilizou-se suco despectinizado da cultivar Gala no processo de crioconcentração e na elaboração do fermentado. Diluiu-se o grau alcoólico para $4,5^{\circ} \mathrm{GL}$, sendo as correções de açúcares com o crioconcentrado e de acidez com ácido cítrico efetuadas com base no resultado da preferência dos consumidores pelo teste de ordenação. Definiu-se a espuma após teste com alginato de propileno glicol. O teor residual de açúcares corrigido com o suco crioconcentrado foi de $50 \mathrm{~g} . \mathrm{L}^{-1}$, aumentando seu o teor de fenólicos e sua atividade antioxidante. Corrigiu-se a acidez para 0,75 g.100 $\mathrm{mL}^{-1}$, tornando-a semelhante à da sidra francesa. A espuma, próximo ao natural, porém mais persistente foi conseguida com adição de alginato de propileno glicol na proporção de $4,0 \mathrm{~g} \cdot \mathrm{hL}^{-1}$. O índice de aceitação do produto foi de $81,63 \%$ com tendência de intenção de compra de aproximadamente $85 \%$, indicando que 0 produto atende ao gosto do consumidor. Desta forma, elaborouse bebida com características da sidra francesa com ótima aceitação pelos consumidores e potencial de mercado.
\end{abstract}

PALAVRAS-CHAVE: CRIOCONCENTRADO; FERMENTADO DE MAÇÃ; FENÓIS; ATIVIDADE ANTIOXIDANTE; AVALIAÇÃO SENSORIAL.

* $\quad$ Mestre em Ciência e Tecnologia de Alimentos, Universidade Estadual de Ponta Grossa (UEPG), Ponta Grossa, PR (e-mail: ricardocarvalhoo@bol.com.br).

** Acadêmica de Engenharia de Alimentos, Bolsista de Iniciação Científica PIBIC/Fundação Araucária, Departamento de Engenharia de Alimentos, UEPG, Ponta Grossa, PR (e-mail: karollinesilva@gmail.com).

*** Professora, Doutora em Tecnologia de Alimentos, Departamento de Engenharia de Alimentos, UEPG, Ponta Grossa, PR (e-mail: deise.rsimoes@gmail.com).

**** Pesquisador Sênior, Bolsista de PP/CNPq, Mestre em Ciência e Tecnologia de Alimentos (MesCTA), UEPG, Ponta Grossa, PR (e-mail: wosiacki@uol.com.br).

$\star * \star \star \star$ Professor, Doutor em Processos Biotecnológicos Agroindustriais, Departamento de Engenharia de Alimentos, UEPG, Ponta Grossa, PR (e-mail: alessandronog@yahoo.com.br). 


\section{INTRODUÇÃO}

Nos últimos 30 anos, a produção de maçãs cresceu mais de 6.000\%. Na safra de 1977/1978 foram produzidas 14.218 toneladas e em 2007/2008 esse número chegou a 900.418 toneladas. Porém, a maior safra registrada foi em 2006/2007, com 993.225 toneladas (FERREIRA, 2009). A produção de maçãs no Brasil está concentrada (99\%) abaixo do Trópico de Capricórnio. O Estado de Santa Catarina responde por $51 \%$ da produção nacional, seguido pelo Rio Grande do Sul (44\%) e Paraná (5\%). Os três grandes pólos produtores são Vacaria (RS), São Joaquim (SC) e Fraiburgo (SC) e as cultivares Gala e Fuji representam mais de 90\% da produção (EPAGRI, 2002; WOSIACKI et al., 2008). Cerca de $20 \%$ a 30\% das maçãs não apresenta qualidade para a comercialização in natura, devido fatores climáticos e fitopatológicos, sendo encaminhadas ao setor agroindustrial de processamento de sucos (clarificado, néctares e concentrado) ou produtos fermentados (sidra e vinagre) e destilados (eau-devie e calvados) (PAGANINI et al., 2004).

As frutas sem pontos de podridão podem ser destinadas ao processamento de suco. A maior parte da produção de suco de maçã é exportada para os Estados Unidos da América sob a forma de suco clarificado concentrado $\left(75^{\circ} \mathrm{Brix}\right)$ para a elaboração de produtos infantis devido à pouca acidez (em média 0,36 g.100 mL-1) e baixa adstringência. O teor de fenóis com média de $311 \mathrm{mg} \cdot \mathrm{L}^{-1}$, especialmente de procianidóis, e a baixa acidez são responsáveis pelo sabor tanante e essenciais para o desenvolvimento do sabor e da qualidade da bebida (WOSIACKI et al., 2008; WOSIACKI e NOGUEIRA, 2010). Frutas de qualidade inferior são encaminhadas para a fabricação do fermentado de maçã, base para a elaboração da sidra, formulação de outras bebidas alcoólicas, vinagres e de destilado de maçã (NOGUEIRA et al., 2007).

O consumo de bebidas fermentadas de maçã vem diminuindo em função da falta de qualidade e de acompanhamento das tendências de mercado. A sidra brasileira tem sido elaborada da mesma forma desde a década de 70 , momento em que foi estilizada para ser semelhante ao vinho branco frisante ou espumante (que "estoura"), além da embalagem ser parecida com a do champanha. Para isso, a formação de cor pela reação de escurecimento enzimático foi eliminada por adições de sulfito na etapa de trituração, o que afeta diretamente a formação de aromas por leveduras oxidativas ou não convencionais presentes na epiderme das frutas. A fermentação alcoólica conduzida de forma rápida promove o aparecimento de aromas com notas "de fermento" que normalmente devem ser corrigidos antes do engarrafamento. O Decreto $\mathrm{n}^{\circ}$. 6.871 (BRASIL, 2009), que regulamenta a Lei no 8.918 (BRASIL, 1994) sobre a padronização, a classificação, o registro, a inspeção, a produção e a fiscalização de bebidas possibilita que a sidra brasileira seja elaborada com adição de água e com elevadas concentrações de açúcar, podendo conter a mesma quantidade encontrada na maçã (cerca de 120,0 g.:-1').

A sidra francesa é completamente diferente. A matéria-prima consiste de maçãs industriais com elevados teores de taninos, que conferem adstringência à bebida e acidez superior a das maçãs comerciais, tornando-a refrescante. A coloração varia do amarelo-claro ao laranjado-escuro, semelhante ao suco de maçã clarificado. Apresenta fermentação alcoólica lenta, obtida pela redução de biomassa (NOGUEIRA et al., 2008), que promove a formação de aromas "frutados e/ou florais" por leveduras não convencionais, atributos muito desejados e procurados pelos consumidores. A fermentação não é conduzida até a exaustão, permitindo a permanência de açúcares residuais da própria fruta e proporcionando baixo grau alcoólico. Tais características distinguem essa bebida, reconhecida como uma das melhores mundialmente (NOGUEIRA e WOSIACKI, 2010).

Os compostos fenólicos da maçã influenciam a cor do suco, seu gosto amargo e a sensação de adstringência na formação de componentes dos aromas e claridade do suco. $\mathrm{O}$ interesse pelos compostos fenólicos reside na sua capacidade antioxidante, que contribui para a proteção dos efeitos prejudiciais de espécies reativas de oxigênio e peroxidação de lipídios que podem estar ligados a condições patológicas como, aterosclerose, câncer e inflamações crônicas (MANGAS et al., 1999; LEE e SMITH, 2000; GOSSÉ et al., 2005; SEERAM e NAIR, 2002). O perfil e a quantidade de compostos fenólicos em sucos de maçãs e sidras dependem do cultivar de maçã, do seu grau de maturação, das 
condições culturais e do tipo de extração durante a operação de prensagem (LEA e ARNOLD, 1978). No processamento, a concentração de fenóis pode ser modificada pela reação de escurecimento enzimático devido à ação da polifenoloxidase (PPO) e formação de precipitados (CLIFF et al., 1991; ZARDO et al., 2008). Dessa forma, as maiores perdas de compostos fenólicos no processamento de maçãs ocorrem pela oxidação durante e após a operação de trituração, devido extração incompleta dos tecidos da fruta e durante a clarificação do suco (SLUIS et al., 2002; SHAHIDI e NACZK, 1995).

A crioconcentração, concentração de alimentos líquidos por congelamento, envolve a cristalização fracionada da água em gelo e sua subsequente remoção sem alteração de outros componentes. Nos sucos, as baixas temperaturas usadas no processo causam alta retenção de compostos aromáticos (FELLOWS, 2006). A concentração por congelamento de suco de maçã pode aumentar até 3 vezes seu teor de fenóis, apenas dobrando-se o teor de açúcares (WIECHETECK et al., 2005).

Uma das mais importantes características de bebidas gaseificadas é a espuma, pois consiste no primeiro atributo percebido pelos consumidores. A sua formação está ligada à presença de pequenas bolhas lentamente liberadas através do líquido e sua persistência são características apreciadas (LIGERBELAIR et al., 1999). As bolhas de gás aumentam a percepção sensorial de vinhos frisantes por transportarem moléculas de aromas (LIGER-BELAIR et al., 2001). A composição química de vinhos influencía a formação de espuma. Compostos nitrogenados, principalmente aminoácidos e polissacarídeos, apresentam correlação positiva com a formação e estabilidade de espumas (ANDRÉSLACUEVA et al., 1996; ANDRÉS-LACUEVA et al., 1997; LÓPEZ-BARAJAS et al., 1998; MORENOARRIBAS et al., 2000). Porém, alguns autores discordam com relação às proteínas de vinhos e sua influência na formação de espuma (PUEYO, MARTIN-ALVAREZ e POLO, 1995). Na sidra, segundo Blanco-Gomis et al. (2007), foi observado que proteínas de massa molecular entre 75,3 e 154,4 kDa são as principais responsáveis pela formação de espuma, afetando diretamente o tempo de estabilidade. Alguns ácidos não voláteis, como o tartárico e o málico, exercem influência positiva na formação de espuma, enquanto o etanol, a acidez volátil e o dióxido de enxofre apresentam contribuição negativa para esse parâmetro (GIRBAU-SOLÁ et al., 2002; LÓPEZ-BARAJAS et al., 1998). Durante o estudo de espuma em bebidas frisantes torna-se necessário avaliar os seguintes parâmetros: [1] altura da espuma (AE), [2] altura de estabilidade da espuma (AEE) e [3] tempo de estabilidade (TE). AE está relacionada com a capacidade de formar espuma e consiste no principal indicador desse parâmetro para fermentados de frutas (GALLART et al., 2004), AEE representa a capacidade de manter o colar estável e TE está relacionado à estabilidade da espuma (BLANCO-GOMIS et al., 2007).

O objetivo deste trabalho foi a elaboração de fermentado frisante de maçã, a partir de maçãs provenientes do descarte comercial, com características de qualidade semelhantes à da sidra francesa.

\section{MATERIAL E MÉTODOS}

\subsection{MAÇÃS}

Na elaboração do produto foi utilizada a cultivar Gala, aproximadamente $100 \mathrm{~kg}$, safra 2007/ 2008, adquirida no comércio da cidade de Ponta Grossa (PR). As frutas foram selecionadas e armazenadas a $10^{\circ} \mathrm{C}$ (refrigeradores) até o momento do seu processamento em suco e fermentado alcoólico. Os reativos utilizados foram pro analysis e os equipamentos e materiais fornecidos pelos Laboratórios de Ciência e Tecnologia de Alimentos do Departamento de Engenharia de Alimentos da Universidade Estadual de Ponta Grossa (UEPG).

\subsection{MICRORGANISMO}

A levedura Saccharomyces cerevisiae r.f. cerevisiae Fermol ${ }^{\circledR}$ Bouquet (AEB Group), comercializada na forma seca ativa, foi utilizada nos experimentos como inóculo de levedura fermentativa. 


\subsection{FERMENTADOR PILOTO}

Desenvolveu-se fermentador em aço inox, com capacidade para 25 litros, resistente à pressão de 2,0 bar (Figura 1), sendo o gás carbônico $\left(\mathrm{CO}_{2}\right)$ adquirido da empresa White Martins. O cilindro utilizado tem capacidade de $5,0 \mathrm{~kg}$ de $\mathrm{CO}_{2}$ com teor de pureza entre 98 a 99\%. O gás foi incorporado na bebida na etapa final, no fermentador piloto mediante sistema desenvolvido para essa finalidade, consistido de válvula em aço inoxidável conectada ao tanque e envolvida com pedra vulcânica porosa (Figura 1 acessório 10), conectado numa válvula de controle de entrada do gás e de controle da pressão interna do cilindro (Figura 1 acessório 8). Usou-se para a dissolução do gás, temperatura próxima de zero grau Celsius, obtida mediante banho termostatizado (Tecnal, TE 2000) com circulação de água fria pela camisa do tanque. $O$ tempo do processo foi de aproximadamente 30 minutos, variando conforme a temperatura. Estabeleceu-se a pressão de gás carbônico no produto em 2,0 bar.

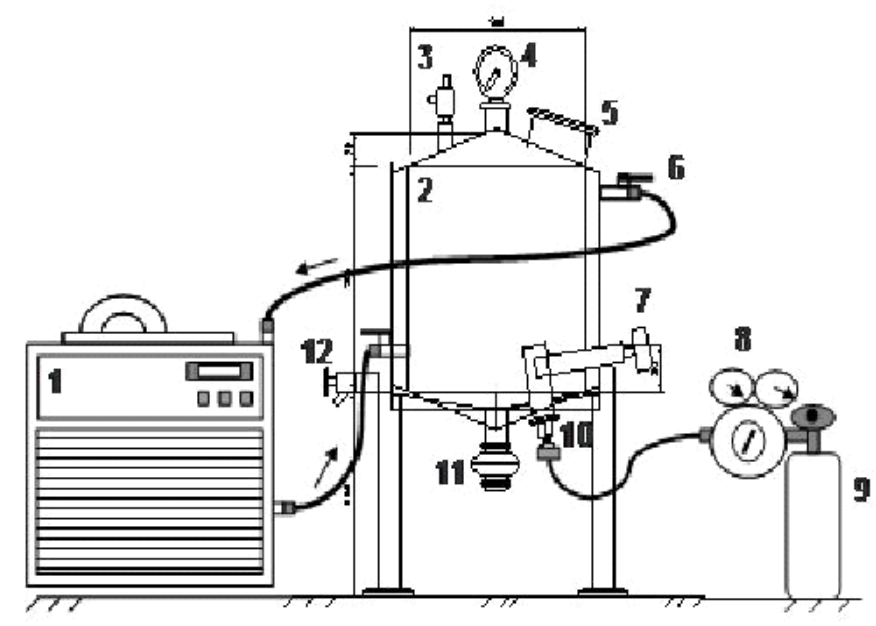

FIGURA 1 - DESENHO DO FERMENTADOR PILOTO

(1) sistema refrigeração; (2) tanque encamisado de aço inox; (3) válvula de segurança regulada para 2 bar; (4) manômetro; (5) abertura para entrada de amostra e limpeza; (6) válvula de saída de água fria; (7) termômetro; (8) válvula reguladora de gás carbônico; (9) cilindro de gás carbônico; (10) válvula para injeção de gás carbônico; (11) dreno e (12) ponto de coleta de amostra ou do produto.

\subsection{SUCO DE MAÇÃ DESPECTINIZADO}

As maçãs foram selecionadas, lavadas e fragmentadas em processador de laboratório (Metvisa, Tipo MPA). Submeteu-se a massa ralada à pressão de 3,0 kgf.cm-2 durante 5 minutos (Prensa hidráulica Eureka, Hoppe Ind. Ltda, Brasil). Não foram utilizados antioxidantes. O suco bruto foi tratado com pectinase (Pectinex $3 X \mathrm{~L}$, Novozymes do Brasil) na concentração de $3,0 \mathrm{~mL}^{\mathrm{hL}} \mathrm{hL}^{-1}$, durante 60 minutos a $45^{\circ} \mathrm{C}$, sendo trasfegado após sedimentação (WOSIACKI et al., 1989). Esse produto foi utilizado no experimento de elaboração da bebida, na obtenção do crioconcentrado e do fermentado de maçã e também no experimento de verificação de perda de fenóis pela clarificação com gelatina.

\subsection{SUCO DE MAÇÃ CRIOCONCENTRADO}

Distribuiu-se o suco varietal de maçã despectinizado em formas de alumínio de $40 \mathrm{~cm} \times 20 \mathrm{~cm}$, as quais foram sobrepostas e intercaladas com folha de polipropileno de $1,0 \mathrm{~cm}$ e condicionadas em freezer horizontal a $-18^{\circ} \mathrm{C}$. Após 24 horas, o produto congelado foi transferido para recipiente de tecido (cheese cloth) e centrifugado a 2800 rpm (WAMKE, Centrífuga Cônsul) até cessar a 
saída de suco da centrífuga, separando dessa forma o gelo do suco concentrado (WIECHETECK et al., 2005).

\subsection{FERMENTADO DE MAÇÃ}

O fermentado de maçã foi elaborado segundo Nogueira et al. (2007). O suco de maçã despectinizado foi transferido para fermentadores esterilizados de 0,5 a 25,0 L. Nos fermentadores de 0,5 L (Erlenmeyer) utilizou-se batoque em solução de metabissulfito de potássio a $300 \mathrm{mg} \cdot \mathrm{L}^{-1}$ (M1005.01AG - Synth). No fermentador piloto, a anaerobiose foi mantida com a pressão de gás carbônico através da válvula de segurança, calibrada para suportar no máximo 2 bar de pressão. Utilizou-se levedura comercial seca ativa Saccharomyces cerevisiae re-hidratada conforme recomendações do fabricante e inoculada na população de 2,0 $\times 10^{6}$ células. $\mathrm{mL}^{-1} \mathrm{em}$ todos os ensaios de fermentação.

\subsection{ELABORAÇÃO DO PRODUTO}

Diluiu-se o fermentado de maçã com água destilada até o grau alcoólico de 4,5GL (Figura 2), que foi utilizado em misturas com suco crioconcentrado nos teores finais de 30,00; 50,00 e 70,00 g.L.-1 de açúcares residuais. Para cada mistura corrigiu-se o pH com ácido cítrico (18427-Biotec) a partir de solução a $30 \%$ nos seguintes teores de acidez 0,$95 ; 0,75 ; 0,60$ e $0,45 \mathrm{~g} \cdot 100 \mathrm{~mL}^{-1}$. As misturas foram analisadas sensorialmente por teste de ordenação-preferência, visando eleger a combinação preferida.

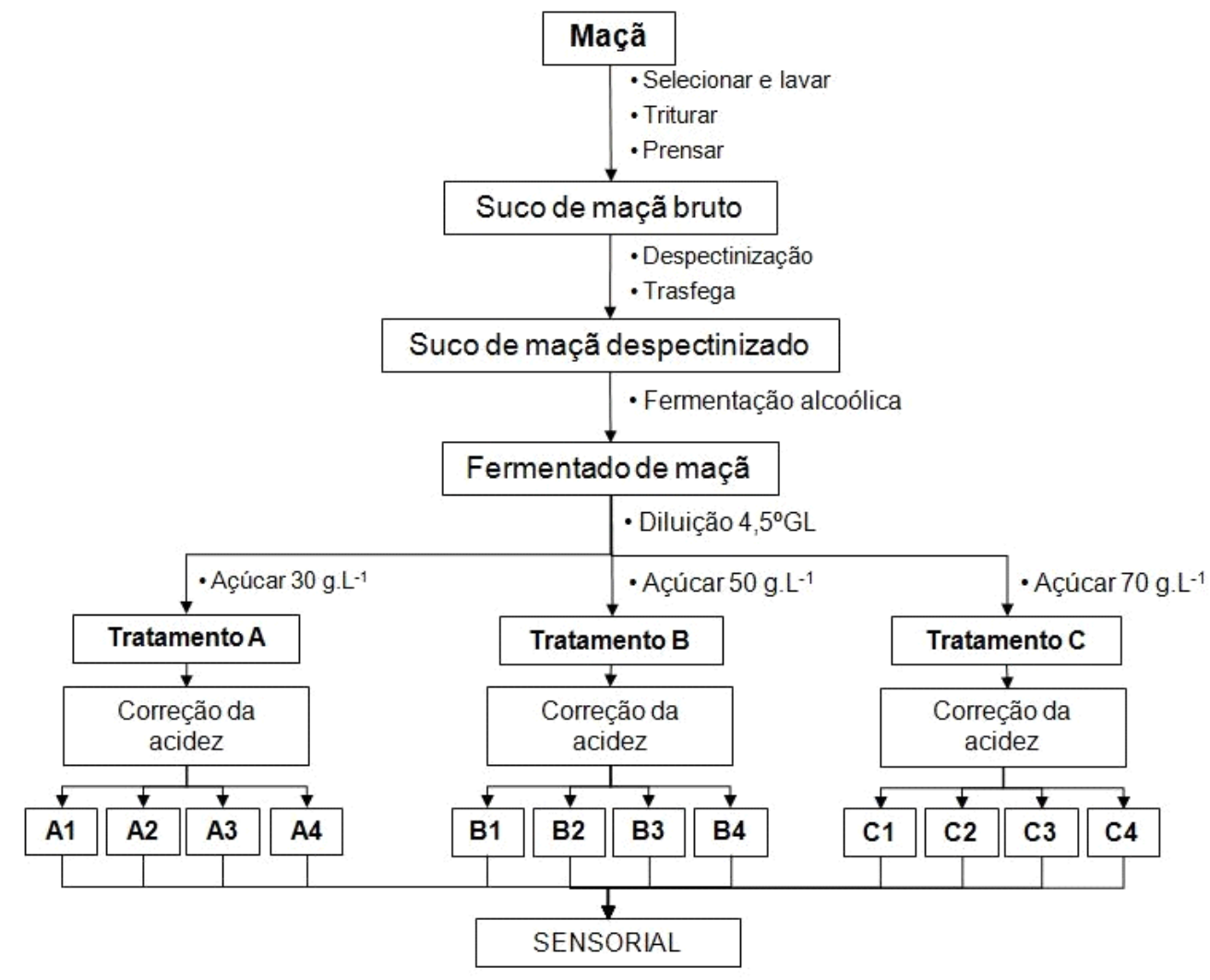

FIGURA 2 - FLUXOGRAMA EXPERIMENTAL DE DESENVOLVIMENTO DA BEBIDA FERMENTADA A PARTIR DE MAÇÃS

Avaliação do açúcar (crioconcentrado) 30 (A); 50 (B) e 70 (C) g.L-1-1 e da acidez 0,90 (1); 0,75 (2); 0,60 (3) e 0,45 (4) $\mathrm{g} .100 \mathrm{~mL}^{-1}$. 


\subsection{MONITORAMENTO DAFERMENTAÇÃO ALCOÓLICA}

Monitorou-se a fermentação pela contagem de leveduras vivas em câmara de Neubauer (XB-K25, SMIC, China) (LEE, ROBINSON e WANG, 1981) e estabeleceu-se a cinética de fermentação pela perda de gás carbônico. Durante a fermentação, o açúcar transformado em etanol libera gás carbônico, determinado pela perda de massa monitorada por sucessivas pesagens do fermentador (ROGER et al., 2002). O grau alcoólico foi determinado por ebuliometria.

\subsection{CONCENTRAÇÃO DO ESTABILIZANTE DE ESPUMA}

Testou-se o alginato de propileno glicol (Kelcoloid) nas concentrações de 3,0; 4,0 e 5,0 g.hL-1. 0 estabilizante foi dissolvido em água a $30^{\circ} \mathrm{C}$ e aquecido até a temperatura de $65^{\circ} \mathrm{C}$ com auxílio de agitador com aquecimento. A solução permaneceu em repouso para equilíbrio da temperatura com a do ambiente, sendo logo em seguida adicionada à bebida em pequenas doses. Foram usadas nos testes, em triplicata, taças de vidro de $12 \mathrm{~cm}$ de altura com $190 \mathrm{~mL}$ de volume. Amostra gaseificada, na temperatura de $10^{\circ} \mathrm{C}$, foi adicionada na mesma vazão até a espuma atingir a borda da taça. Nesse momento determinou-se o tempo de persistência da espuma e suas características visuais.

\subsection{ANÁLISES FÍSICO-QUÍMICAS}

Os teores de glucose foram determinados por método enzimático e os açúcares redutores pelo método clássico de Somogyi-Nelson, conforme descrito por Tanner e Brunner (1985), expressos em g. $100 \mathrm{~mL}^{-1}$, enquanto a frutose foi calculada por diferença. A sacarose para ser analisada por essa técnica foi, previamente, hidrolisada com $\mathrm{HCl}$ concentrado $(5,0 \mathrm{~mL}$ de amostra/1,0 $\mathrm{mL}$ de ácido). A

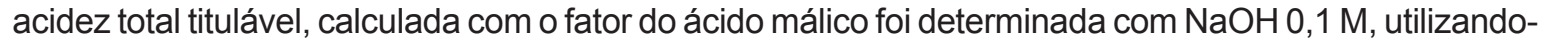
se fenolftaleína $1 \%$ como indicador (IAL, 2008). Analisou-se a acidez volátil pelo arraste de vapor e titulação com $\mathrm{NaOH} 0,1 \mathrm{~N}$ na presença de fenolftaleína $1 \%$ como indicador, usando-se no cálculo o fator do ácido acético (CHAVARRIA, et al., 2008). O teor de álcool etílico foi determinado por ebuliometria e o teor de nitrogênio total pelo clássico método de Kjedhal, segundo Julien, Trioli e Dulau (2001). Os compostos fenólicos foram determinados pelo método de Folin-Ciocalteau (SINGLETON e ROSSI, 1965). Em tubo de ensaio foram adicionados $8,4 \mathrm{~mL}$ de água destilada, $100 \mu \mathrm{L}$ de amostra ou padrão de catequina, devidamente diluída, e $500 \mu \mathrm{L}$ do reativo de Folin-Ciocalteau. Após 3 min de reação adicionou-se $1,0 \mathrm{~mL}$ de carbonato de sódio saturado em cada tubo, que foram agitados. Depois de $1 \mathrm{~h}$ efetuou-se a leitura da absorbância em espectrofotômetro (Shimadzu - Mod. UV-Mini 1240) a 720 nm, tendo como branco a solução contendo os reativos da análise e o inibidor enzimático. Os resultados foram expressos em mg. L-1 de fenólicos totais, utilizando-se catequina como padrão (200 mg. L-1).

\subsection{DETERMINAÇÃO DA ATIVIDADEANTIOXIDANTE}

Para a determinação da atividade antioxidante utilizou-se o método de FRAP, descrito por Benzie e Strain (1996) e Pulido, Bravo e Saura-Calixto (2000). Como padrão usou-se o reativo ácido 6-hidroxi-2,5,7,8-tetrametilchroman-2-carboxílico (TROLOX - Flucka Chemicals Suisse - Cód. 56510) em concentração apropriada para a diluição realizada em cada amostra. Em seguida, 3,0 mL do reagente FRAP e 0,1 mL do padrão ou amostra foram adicionados em tubo de ensaio e a leitura da absorbância realizada a $593 \mathrm{~nm}$, utilizando-se o reagente FRAP como branco. O resultado foi expresso como $\mu \mathrm{mol}$ de redução de ferro/poder antioxidante (valor de FRAP).

\subsection{AVALIAÇÃO DAPREFERÊNCIA (TESTE DE ORDENAÇÃO)}

As avaliações sensoriais dos produtos elaborados foram realizadas após aprovação do projeto de pesquisa pela Comissão de Ética em Pesquisa (COEP), de acordo com o parecer $n^{\circ}$ 44/2008 
referente ao protocolo 11242/08. Todos os julgadores estavam cientes desse protocolo de pesquisa e participaram das avaliações sensoriais de livre e espontânea vontade, sendo informados que poderiam desistir dos trabalhos em qualquer momento da pesquisa. Participaram da avaliação sensorial de preferência dos fermentados de maçãs 50 pessoas, distribuídas entre alunos de graduação e pós-graduação, professores e funcionários administrativos da UEPG. O teste de ordenação NBR 13.170 (ABNT, 1994) foi aplicado para os fermentados do grupo A (30 g.L-1 de açúcar residual com os teores de acidez 0,90 (1); 0,75 (2); 0,60 (3) e 0,45 (4) g. $100 \mathrm{~mL}^{-1}$ ), grupo B (50 g. $\mathrm{L}^{-1}$ de açúcar residual com os mesmos teores de acidez) e grupo $\mathrm{C}$ (70 g.L-1 de açúcar residual com os mesmos teores de acidez) (Figura 2). Primeiramente, aplicou-se o teste de ordenação para cada grupo, visando definir a combinação do teor de açúcar e acidez preferida pelos consumidores nas concentrações propostas. Após as avaliações, a amostra preferida em cada grupo foi novamente submetida ao teste de ordenação a fim de eleger o produto preferido pelos consumidores. O teste foi realizado em cabines individuais sob luz branca no Laboratório de Análise Sensorial da UEPG. As amostras foram codificadas com números aleatórios e servidas aos julgadores em taças formato tulipa, confeccionadas em policloreto de vinila (PVC) transparente com $55 \mathrm{~mL}$ de capacidade. As amostras foram mantidas refrigeradas até o momento da avaliação $\left(7^{\circ} \mathrm{C}\right)$, sendo servida a quantidade de $30 \mathrm{~mL}$. Foi solicitado aos julgadores que, entre uma amostra e outra, lavassem a boca com água para retirada do gosto residual da amostra anterior e que ordenassem as amostras com relação à preferência (FERREIRA et al., 2000), colocando-as em ordem decrescente (a amostra preferida em primeiro lugar e assim sucessivamente), conforme modelo proposto na Figura 3.

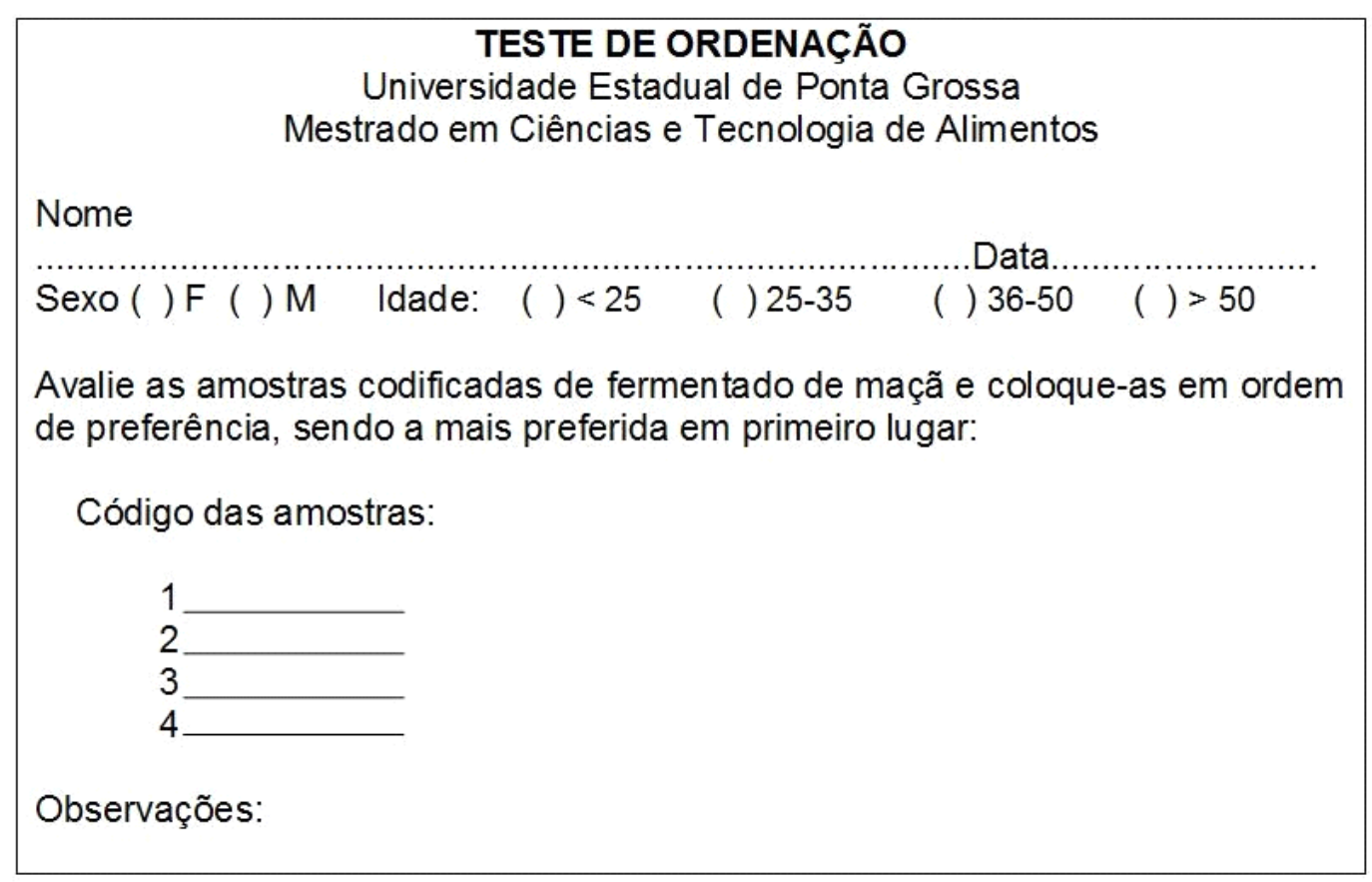

\section{FIGURA 3 - FICHA DE TOMADA DE DADOS PARA AVALIAÇÃO DA PREFERÊNCIA DA BEBIDA FRISANTE DE MAÇÃ}

\subsection{TESTE SENSORIAL DE ACEITABILIDADE DABEBIDA}

A aceitabilidade do fermentado frisante de maçã foi avaliada de acordo com a metodologia descrita por FARIA e YOTSUYANAGI (2002). Participaram da avaliação 168 consumidores, compreendendo alunos de graduação, pós-graduação, professores e funcionários da UEPG (parecer aprovado pela $\operatorname{COEP~} n^{\circ} 44 / 2008$ ). A amostra de fermentado frisante de maçã foi codificada com números aleatórios e servida refrigerada $\left(7^{\circ} \mathrm{C}\right)$ aos consumidores em taças formato tulipa na quantidade de $30 \mathrm{~mL}$. Aos consumidores foi solicitado que avaliassem a amostra de acordo com a escala proposta 
pela NBR 14.141 (ABNT, 1998) com relação à aceitabilidade. A intenção de compra do produto foi determinada perante a atitude do consumidor em situação hipotética de compra, usando-se escala hedônica de 7 pontos (Figura 4).

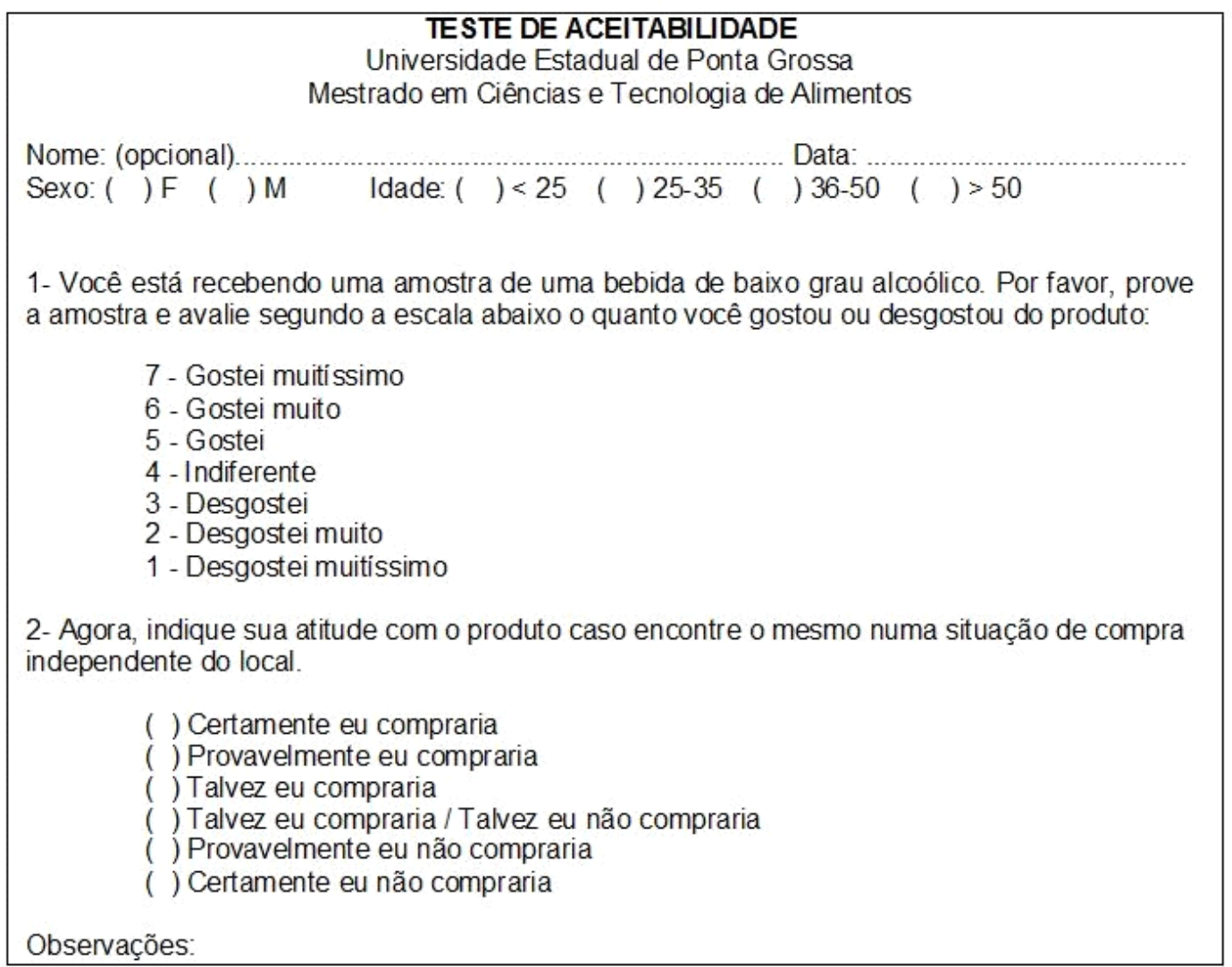

\section{FIGURA 4 - FICHA DE TOMADA DE DADOS PARA AVALIAÇÃO DA ACEITABILIDADE DO FERMENTADO FRISANTE DE MAÇÃ}

\subsection{ANÁLISE ESTATÍSTICA}

A análise dos dados referentes à preferência das amostras por ordenação foi realizada segundo a tabela de Newell e Mac Farlane proposta na NBR 13.170 (ABNT, 1994), que fornece valores da diferença crítica entre os somatórios de ordenação a partir do número de julgamentos e número de amostras avaliadas. Assim, caso a diferença entre a soma das ordens de duas amostras for maior ou igual ao número tabelado pode-se dizer que existem diferenças significativas de preferência entre elas, ao nível de probabilidade considerado. O índice de aceitabilidade do fermentado frisante de maçã foi obtido pela média das respostas dos consumidores. A atitude de compra do produto foi demonstrada na forma de histogramas e porcentagem de intenção de compra.

\section{RESULTADOS E DISCUSSÃO}

\subsection{CARACTERÍSTICAS FÍSICO-QUÍMICAS DOS PRODUTOS ISOLADOS}

Na Tabela 1 podem ser observados os valores médios da composição físico-química do suco de maçã da cultivar Gala, utilizado para elaborar o crioconcentrado e o fermentado de maçã. Os valores de açúcares atestam o grau de maturidade das frutas e correspondem aos encontrados por Wosiacki et al. (2008). Segundo a classificação de Drilleau (1991), as frutas são consideradas boas 
(130 - 138 g.L-1) em relação ao teor total de açúcares. Os baixos teores de acidez $\left(<0,45 \mathrm{~g} .100 \mathrm{~mL}^{-1}\right)$ indicam que esse suco é proveniente de maçãs produzidas para o consumo in natura (PAGANINI et al., 2004). O teor de fenóis de $353 \mathrm{mg} . \mathrm{L}^{-1}$ mostrou-se semelhante aos valores médios de sucos de maçãs provenientes de maçãs de mesa (WOSIACKI et al., 2008). Os teores de nitrogênio de $94,97 \mathrm{mg} \cdot \mathrm{L}^{-1}$ permitem classificar o mosto em concentrações normais $\left(75-149 \mathrm{mg} \cdot \mathrm{L}^{-1}\right)$ para o desenvolvimento das leveduras durante o processo de fermentação alcoólica de mosto de maçãs (NOGUEIRA, QUÉRÉ e BULDIN, 2003).

Os valores físico-químicos do suco crioconcentrado com base nos açúcares indicam concentração de aproximadamente 3,3 vezes. Entretanto, a atividade antioxidante e o teor de nitrogênio do crioconcentrado aumentaram, aproximadamente, cinco (5) e quatro (4) vezes, respectivamente (Tabela 1).

\section{TABELA 1 - COMPOSIÇÃO FÍSICO-QUÍMICA DO SUCO DE MAÇÃ DESPECTINIZADO E DO SEU CRIOCONCENTRADO (CV. GALA)}

\begin{tabular}{|c|c|c|}
\hline ANÁLISES FÍSICO-QUÍMICAS & SUCO & CRIOCONCENTRADO \\
\hline $\begin{array}{l}\text { ART g.100 mL-1 } \\
\text { AR g.100 } \mathrm{mL}^{-1} \\
\text { Glucose g. } 100 \mathrm{~mL}^{-1} \\
\text { Frutose g.100 mL } \\
\text { Sacarose g. } 100 \mathrm{~mL}^{-1} \\
\text { Nitrogênio mg. } \mathrm{L}^{-1} \\
\text { Acidez titulável, g.100 } \mathrm{mL}^{-1} \\
\text { Fenóis totais, mg. } \mathrm{L}^{-1} \\
\text { Frap, } \mu \text { Mol }\end{array}$ & $\begin{array}{c}13,55 \pm 0,26 \\
11,33 \pm 0,39 \\
2,61 \pm 0,02 \\
8,72 \pm 0,41 \\
2,21 \pm 0,56 \\
94,97 \pm 0,001 \\
0,25 \pm 0,01 \\
353 \pm 6 \\
3462 \pm 139\end{array}$ & $\begin{array}{c}44,45 \pm 0,01 \\
40,64 \pm 1,74 \\
8,26 \pm 0,09 \\
32,39 \pm 1,70 \\
4,81 \pm 0,34 \\
396,45 \pm 0,01 \\
0,70 \pm 0,01 \\
991 \pm 24 \\
11429 \pm 598\end{array}$ \\
\hline
\end{tabular}

Nota: (ART) açúcar redutor total; (AR) açúcar redutor.

A fermentação alcoólica foi conduzida no fermentador de $25 \mathrm{~L}$, com 20 litros de volume útil, em anaerobiose durante 10 dias à temperatura ambiente $\left(20-27^{\circ} \mathrm{C}\right)$. Em pequenos fermentadores de $500 \mathrm{~mL}$ (erlenmeyer) monitorou-se a fermentação e a perda de massa por liberação de gás carbônico (durante 15 dias) por pesagens do fermentador (Figura 5). Observou-se que após 6 dias de fermentação, com população inicial de $1,0 \times 10^{7}$ células. $\mathrm{mL}^{-1}$, os açúcares fermentescíveis foram totalmente consumidos, produzindo o total de $6,7^{\circ} \mathrm{GL}$ de etanol. Esse resultado, confirmado pela estabilização do peso do fermentador no mesmo tempo, indica o fim da liberação de gás carbônico. Para atingir a população máxima de leveduras $\left(1,0 \times 10^{8}\right.$ células. $\left.\mathrm{mL}^{-1}\right)$ foram consumidos aproximadamente 60 mg. L-1 de nitrogênio total. Segundo Nogueira, Quere e Buldin (2003), de 20 a 30 mg. L-1 de nitrogênio em mosto de maçãs são constituídos de aminoácidos não assimiláveis, justificando o residual encontrado (Figura 5B). Após 7 dias de fermentação, as leveduras iniciaram a fase de declínio celular e devido à autólise das células com liberação de compostos nitrogenados no meio, o teor de nitrogênio total aumentou para próximo de $60 \mathrm{mg} \cdot \mathrm{L}^{-1}$. Nessas condições, o processo de fermentação alcoólica terminou em 5 dias, tempo relativamente curto e interessante para indústria. Porém, esses compostos nitrogenados liberados no fermentado de maçã podem participar da formação de espuma na bebida, pois foram identificadas proteínas de massa molecular entre 75,3 e 154,4kDa em sidras, que seriam as responsáveis pela formação da espuma característica (BLANCO-GOMIS et al., 2007). Na maçã, existem apenas traços de proteínas, sendo o seu teor em compostos nitrogenados constituído de aminoácidos (LEA e DRILLEAU, 2003). 


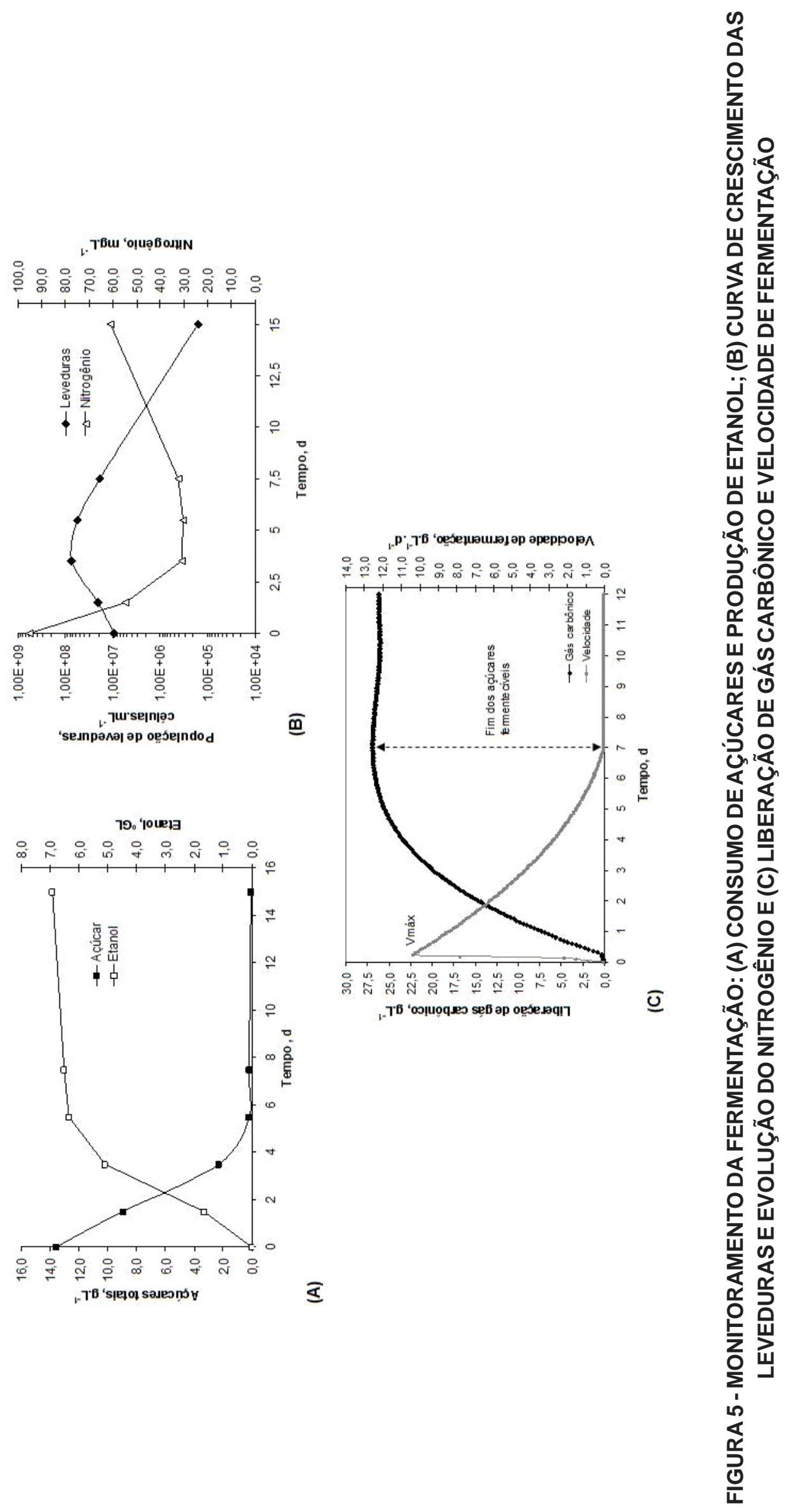


Na Tabela 2 pode ser observada a composição físico-química do fermentado de maçã após 10 dias de fermentação. Os valores médios de açúcar confirmam o resultado da perda de massa. O teor alcoólico final de $6,9^{\circ} \mathrm{GL}$ corresponde ao teor de açúcar utilizado pela levedura. A acidez do fermentado mostrou-se semelhante à acidez do suco de maçã. O teor de fenóis diminuiu $16 \%$ com o processo fermentativo, próximo ao encontrado (12\%) por Zardo et al. (2008) para a mesma cultivar. Porém, a atividade antioxidante diminuiu 33\% em relação ao suco. Nogueira et al. (2008) observaram pequena redução no teor de fenóis durante a fermentação, sendo constatada diminuição na concentração de alguns compostos e aumento de outros.

Na elaboração do produto, o fermentado de maçã foi diluído com água potável até o valor de $4,5^{\circ} \mathrm{GL}$ (Tabela 2) a fim de se padronizar o teor alcoólico da bebida. O fermentado diluído foi corrigido com suco crioconcentrado para aumentar os teores de açúcares, fenóis totais e atividade antioxidante.

TABELA 2 - COMPOSIÇÃO FÍSICO-QUÍMICA DOS FERMENTADOS DE MAÇÃ PADRÃO E DILUÍDO PARA $4,5^{\circ} \mathrm{GL}$

\begin{tabular}{lcc}
\hline ANÁLISES FÍSICO-QUÍMICAS & FERMENTADO & FERMENTADO (DILUÍDO) \\
\hline ART g.100 mL & & \\
AR g.100 $\mathrm{mL}^{-1}$ & $0,05 \pm 1,478$ & $0,04 \pm 0,001$ \\
Glicose g.100 mL-1 & $0,04 \pm 0,004$ & $0,03 \pm 0,226$ \\
Frutose g.100 mL & $0,003 \pm 0,001$ & $0,002 \pm 0,001$ \\
Sacarose g.100 mL & $0,04 \pm 0,01$ & $0,03 \pm 0,01$ \\
Nitrogênio $\mathrm{mg}^{-1}$ & $0,02 \pm 0,01$ & $0,01 \pm 0,01$ \\
Acidez volátil g.100 mL & $60,88 \pm 0,001$ & $46,95 \pm 0,001$ \\
Acidez titulável, $\mathrm{g} \cdot 100 \mathrm{~mL}^{-1}$ & $0,02 \pm 0,001$ & $0,01 \pm 0,017$ \\
Teor alcoólico, ${ }^{\circ} \mathrm{GL}$ & $0,23 \pm 0,004$ & $0,13 \pm 0,007$ \\
Fenóis totais, $\mathrm{mg}^{-1}$ & $6,90 \pm 0,020$ & $4,45 \pm 0,050$ \\
Frap, $\mu$ Mol & $296 \pm 15$ & $196 \pm 17$ \\
& $2308 \pm 161$ & $1517 \pm 80$ \\
\hline
\end{tabular}

Nota: (ART) açúcar redutor total; (AR) açúcar redutor.

\subsection{AVALIAÇÃO DA PREFERÊNCIA DOS FERMENTADOS FRISANTES DE MAÇÃ}

Para avaliação da preferência dos fermentados frisantes de maçã (cultivar Gala), as concentrações de açúcar avaliadas foram de 30 (A), 50 (B) e 70 (C) g.L.-1 e as de acidez 0,90; 0,75; 0,60 e $0,45 \mathrm{~g} .100 \mathrm{~mL}^{-1}$. Esses valores foram definidos após a realização de testes em laboratório com 50 participantes, sendo $53 \%$ mulheres e $47 \%$ homens. Os consumidores representaram o público jovem, sendo mais de $90 \%$ deles com idade inferior a 35 anos.

$\mathrm{Na}$ Tabela 3 pode ser observada a somatória das ordens obtidas a partir do teste de ordenação para preferência com três (3) tratamentos (A, B e C) e quatro (4) teores de acidez. No grupo do tratamento $A$, o fermentado denominado $A 1$ foi o preferido e o $A 4$ o menos preferido. A partir da diferença mínima significativa (DMS) obtida pela tabela de Newell e Mac Farlane (QUEIROZ e TREPTOW, 2006) para cinquenta julgamentos e quatro fermentados obteve-se o valor 34 . De acordo com esse valor pode-se dizer que não foi observada diferença significativa ao nível de $5 \%$ de probabilidade entre os fermentados A2, A3 e A4, sendo o fermentado A1 diferente dos demais. Conforme os resultados podese dizer que para o teor de açúcar de $30 \mathrm{~g} \cdot \mathrm{L}^{-1}$, a bebida com acidez de $0,90 \mathrm{~g} \cdot 100 \mathrm{~mL}^{-1}$ foi a preferida. No grupo do tratamento B, os valores de B1, B3 e B4 ficaram muito próximos não sendo significativos ao nível de probabilidade de $5 \%$. A bebida preferida na concentração de açúcar de $50 \mathrm{~g} \cdot \mathrm{L}^{-1}$ foi o fermentado B2, com correção de acidez para $0,75 \mathrm{~g} .100 \mathrm{~mL}^{-1}$. O fermentado C3, do grupo C, foi o 
preferido na concentração de açúcar de $70 \mathrm{~g} \cdot \mathrm{L}^{-1}$ e com acidez de $0,60 \mathrm{~g} \cdot 100 \mathrm{~mL}-1$. O fermentado $\mathrm{C} 2$ foi o menos preferido. Entre os demais fermentados não foi detectada diferença significativa ao nível de probabilidade de 5\%, com base na tabela de Newell e Mac Farlane (QUEIROZ e TREPTOW, 2006). De acordo com os resultados obtidos pode-se dizer que para o teor de açúcar de $70 \mathrm{~g} . \mathrm{L}^{-1}$, o fermentado com acidez de $0,60 \mathrm{~g} .100 \mathrm{~mL}^{-1}$ foi o preferido.

\section{TABELA 3 - RESULTADOS DO TESTE DE ORDENAÇÃO-PREFERÊNCIA PARA AS AMOSTRAS DE FERMENTADO FRISANTE DE MAÇÃS PADRONIZADO COM 30 (A), 50 (B) E 70 G.L ${ }^{-1}$ (C) DE AÇÚCAR E COM ACIDEZ DE 0,90 (1); 0,75 (2); 0,60 (3) E 0,45 G.100 mL-1 (4)}

\begin{tabular}{cc|cc|cc}
\hline $\begin{array}{c}\text { Tratamento } A \\
\text { (30 g. } L^{-1} \text { de açúcar) }\end{array}$ & $\begin{array}{c}\Sigma \\
\text { das ordens }\end{array}$ & $\begin{array}{c}\text { Tratamento } \mathrm{B} \\
\left(50 \mathrm{~g} \cdot \mathrm{L}^{-1} \text { de açúcar }\right)\end{array}$ & $\begin{array}{c}\Sigma \\
\text { das ordens }\end{array}$ & $\begin{array}{c}\text { Tratamento C } \\
\left(70 \mathrm{~g} . \mathrm{L}^{-1} \text { de açúcar }\right)\end{array}$ & $\begin{array}{c}\Sigma \\
\text { das ordens }\end{array}$ \\
\hline $\mathrm{A} 1$ & $87^{\mathrm{b}}$ & $\mathrm{B} 1$ & $128^{\mathrm{a}}$ & $\mathrm{C} 1$ & $129^{\mathrm{a}}$ \\
$\mathrm{A} 2$ & $123^{\mathrm{a}}$ & $\mathrm{B} 2$ & $85^{\mathrm{b}}$ & $\mathrm{C} 2$ & $157^{\mathrm{a}}$ \\
$\mathrm{A} 3$ & $134^{\mathrm{a}}$ & $\mathrm{B} 3$ & $138^{\mathrm{a}}$ & $\mathrm{C} 3$ & $90^{\mathrm{b}}$ \\
$\mathrm{A} 4$ & $156^{\mathrm{a}}$ & $\mathrm{B} 4$ & $149^{\mathrm{a}}$ & $\mathrm{C} 4$ & $124^{\mathrm{a}}$ \\
\hline
\end{tabular}

DMS = diferença mínima significativa $=34$ por Newell e Mac Farlane; totais de ordenação seguida pela mesma letra na coluna não diferem significativamente entre si $(5 \%)$. Avaliação feita com 50 participantes.

Na Tabela 4 são apresentados os resultados da ordenação-preferência para as combinações preferidas de açúcares e acidez. A amostra B2 apresentou a menor soma de ordem, sendo a preferida. Notou-se tendência pela combinação meio ácido e doce, reportada pelo valor intermediário de açúcar e acidez nessa amostra. Essa característica é observada em frisantes de frutas e bebidas não alcoólicas carbonatadas. Sabe-se que existe relação entre doçura e acidez e que um estímulo pode se sobrepor ou suprimir a percepção sensorial de outro. Pode-se dizer que a adaptação do estímulo doce aumenta o sabor áspero dos ácidos e vice-versa.

TABELA 4 - RESULTADOS DO TESTE DE ORDENAÇÃO-PREFERÊNCIA PARA AS AMOSTRAS DE FERMENTADO FRISANTE DE MAÇÃS COM TRÊS COMBINAÇÕES DE AÇÚCAR E ACIDEZ

\begin{tabular}{|c|c|c|c|}
\hline Amostra & $\begin{array}{c}\text { A1 } \\
\text { (Açúcar: } 30,00 \mathrm{~g} \cdot \mathrm{L}^{-1} \mathrm{e} \\
\text { acidez: } 0,90 \mathrm{~g} \cdot 100 \mathrm{~mL}^{-1} \text { ) }\end{array}$ & $\begin{array}{c}\text { B2 } \\
\text { (Açúcar: } 50,00 \mathrm{~g} . \mathrm{L}^{-1} \mathrm{e} \\
\text { acidez: } 0,75 \mathrm{~g} .100 \mathrm{~mL}^{-1} \text { ) }\end{array}$ & $\begin{array}{c}\text { C3 } \\
\text { (Açúcar: } 70,00 \mathrm{~g} \cdot \mathrm{L}^{-1} \mathrm{e} \\
\text { acidez: } 0,60 \mathrm{~g} .100 \mathrm{~mL}^{-1} \text { ) }\end{array}$ \\
\hline Total & $193^{\mathrm{a}}$ & $136^{\circ}$ & $171^{\mathrm{a}}$ \\
\hline
\end{tabular}

NOTA: DMS =diferença mínima significativa = 34 por Newell e Mac Farlane; totais de ordenação seguidos pela mesma letra não diferem significativamente entre si (5\%). Avaliação feita com 50 participantes.

De acordo com os resultados obtidos, o fermentado frisante de maçã preferido pelos consumidores continha $50 \mathrm{~g} \cdot \mathrm{L}^{-1}$ de açúcar e $0,75 \mathrm{~g} \cdot 100 \mathrm{~mL}^{-1}$ de acidez.

Na Tabela 5 pode ser observada a composição físico-química do fermentado diluído, corrigido com suco de maçã crioconcentrado para $50 \mathrm{~g} \cdot \mathrm{L}^{-1}$ de açúcares. Esse valor é considerado suave para a sidra francesa, $>42 \mathrm{~g} \cdot \mathrm{L}^{-1}$ (LEA e DRILLEAU, 2003) e para a sidra brasileira, > $20 \mathrm{~g} \cdot \mathrm{L}^{-1}$ (NOGUEIRA e WOSIACKI, 2005), porém sabe-se que o brasileiro prefere bebidas adocicadas e que os europeus apreciam as mais amargas com baixa doçura. A correção com o suco crioconcentrado, além de dobrar os valores de nitrogênio total, fenóis totais e atividade antioxidante em relação ao fermentado diluído, enriqueceu o aroma do 
fermentado que apresentou características de produto frutado com leve percepção de aroma de maçã. $A$ sidra francesa é reconhecida por apresentar aroma com nota floral e frutado (LEA e DRILLEAU, 2003). O teor de compostos fenólicos no fermentado corrigido ficou acima do valor observado para o suco, porém não ressaltou a adstringência e o teor de atividade antioxidante mostrou-se semelhante ao do suco (Tabela 1). A acidez, que proporciona a sensação de refrescância ao produto foi corrigida para $0,75 \mathrm{~g} .100 \mathrm{~mL}^{-1} \mathrm{com}$ adição de ácido cítrico. Segundo Beech (1972) e Drilleau (1991), os mostos de maçã com acidez acima de $0,45 \mathrm{~g} \cdot 100 \mathrm{~mL}^{-1} \mathrm{e}$ teor de fenóis totais maior que $200 \mathrm{mg}^{\mathrm{L} \mathrm{L}^{-1}}$ são classificados como ácido-amargo. Assim, a formulação final proporcionou equilíbrio entre açúcar, taninos e acidez com base nos resultados dos testes sensoriais realizados, definindo o "corpo" da bebida. Na situação francesa torna-se necessária a mistura de cultivares para obtenção de balanço adequado de açúcares, acidez e taninos, parâmetros significativos para a obtenção de produto de qualidade, dificilmente encontrado numa única cultivar (LEAe DRILLEAU, 2003). O residual de açúcares normalmente está situado entre $<28 \mathrm{~g} . \mathrm{L}^{-1}$ (seca) e $28-42 \mathrm{~g} . \mathrm{L}^{-1}$ (semi-seca), o que intensifica o gosto amargo e ácido (DRILLEAU, 1991).

\section{TABELA 5 - COMPOSIÇÃO FÍSICO-QUÍMICA DO FERMENTADO DE MAÇÃ DILUÍDO E CORRIGIDO COM SUCO CRIOCONCENTRADO}

\begin{tabular}{|c|c|}
\hline Análises físico-químicas & Fermentado (corrigido) \\
\hline ART g.100 $\mathrm{mL}^{-1}$ & $4,82 \pm 0,23$ \\
\hline AR g. $100 \mathrm{~mL}^{-1}$ & $4,16 \pm 0,23$ \\
\hline Glicose g.100 mL-1 & $1,23 \pm 0,01$ \\
\hline Frutose $\mathrm{g} .100 \mathrm{~mL}^{-1}$ & $3,71 \pm 0,17$ \\
\hline Sacarose g.100 $\mathrm{mL}^{-1}$ & $0,66 \pm 0,10$ \\
\hline Nitrogênio mg. $\mathrm{L}^{-1}$ & $91,84 \pm 0,01$ \\
\hline Acidez volátil g.100 $\mathrm{mL}^{-1}$ & $0,02 \pm 0,01$ \\
\hline Acidez titulável, g.100 $\mathrm{mL}^{-1}$ & $0,74 \pm 0,01$ \\
\hline Teor alcoólico, ${ }^{\circ} \mathrm{GL}$ & $4,49 \pm 0,036$ \\
\hline Fenóis totais, $\mathrm{mg} \mathrm{L}^{-1}$ & $429 \pm 40$ \\
\hline Frap, $\mu \mathrm{Mol}$ & $3195 \pm 164$ \\
\hline
\end{tabular}

Nota: (ART) açúcar redutor total; (AR) açúcar redutor;

\subsection{ESTABILIZANTE DE ESPUMA}

Observou-se pequena formação de espuma no produto gaseificado que se desintegrava rapidamente em testes prévios. Elaborou-se, então, ensaio com diferentes adições do estabilizante alginato propileno glicol com a finalidade de manter por mais tempo a espuma natural do produto. A concentração de $5,0 \mathrm{~g} \cdot \mathrm{hL}^{-1}$ do estabilizante proporcionou espuma alta e espessa com persistência $>1,5$ minutos. Na concentração de $3,0 \mathrm{~g} \cdot \mathrm{hL}^{-1}$ (utilizado em cervejaria), a espuma ficou quebradiça com persistência inferior a 40 segundos. Com $4,0 \mathrm{~g} \cdot \mathrm{hL}^{-1}$, a espuma mostrou-se semelhante à espuma natural, porém com boa estabilidade (persistência de 1,20 a 1,30 minutos), sendo essa a concentração escolhida para ser adicionada ao produto.

\subsection{AVALIAÇÃO DA ACEITABILIDADE DO FERMENTADO FRISANTE DE MAÇÃS}

A porcentagem de homens e mulheres que participaram da avaliação sensorial foi de $52 \%$ e $48 \%$, respectivamente. Das 168 pessoas que participaram da avaliação de aceitabilidade do fermentado frisante de maçã, $62 \%$ (34\% mulheres e 28\% homens) pertenciam à faixa etária menor que 25 anos. Do total de participantes, $88 \%$ informaram idade inferior a 35 anos, caracterizando a predominância de público jovem.

A partir dos 168 resultados, a média de aceitabilidade obtida para a amostra de fermentado 
frisante de maçã foi de 5,72 na escala hedônica de 1 a 7 . Transformando o valor médio em índice de aceitabilidade pode-se dizer que o fermentado frisante de maçã obteve índice de 81,63\%, considerado muito bom e com boas perspectivas de mercado. Observa-se no histograma representado na Figura 6A que a maior frequência de notas apareceu na parte positiva da escala (entre as categorias "gostei, gostei muito e gostei muitíssimo"), somando 92,29\% entre esses grupos. Tal resultado é satisfatório, pois se trata de produto novo. Suas características diferenciadas atenderam ao gosto do consumidor em função da menor graduação alcoólica, cor atraente e a presença de espuma que melhora sua aparência. Essas características foram citadas com maior frequência no local destinado aos comentários na ficha de avaliação da amostra. Apenas pequena parcela $(<5 \%)$ dos julgadores atribuiu notas correspondentes a "desgostar" do produto.

Analisando os resultados apresentados sob a forma de histograma (Figura 6B), que reporta a atitude dos consumidores perante o produto, observa-se forte tendência de intenção de compra por parte de aproximadamente $85 \%$ dos julgadores, considerando a soma das três últimas categorias. Apenas $6 \%$ dos julgadores ficaram indecisos, e menos de $8,5 \%$ não comprariam o produto. Esses resultados indicam que a bebida apresenta potencial de mercado significativo e a possibilidade de ser realizada a avaliação da aceitabilidade em grande escala em diversas regiões do Brasil, ou nas regiões com maior consumo de bebidas.
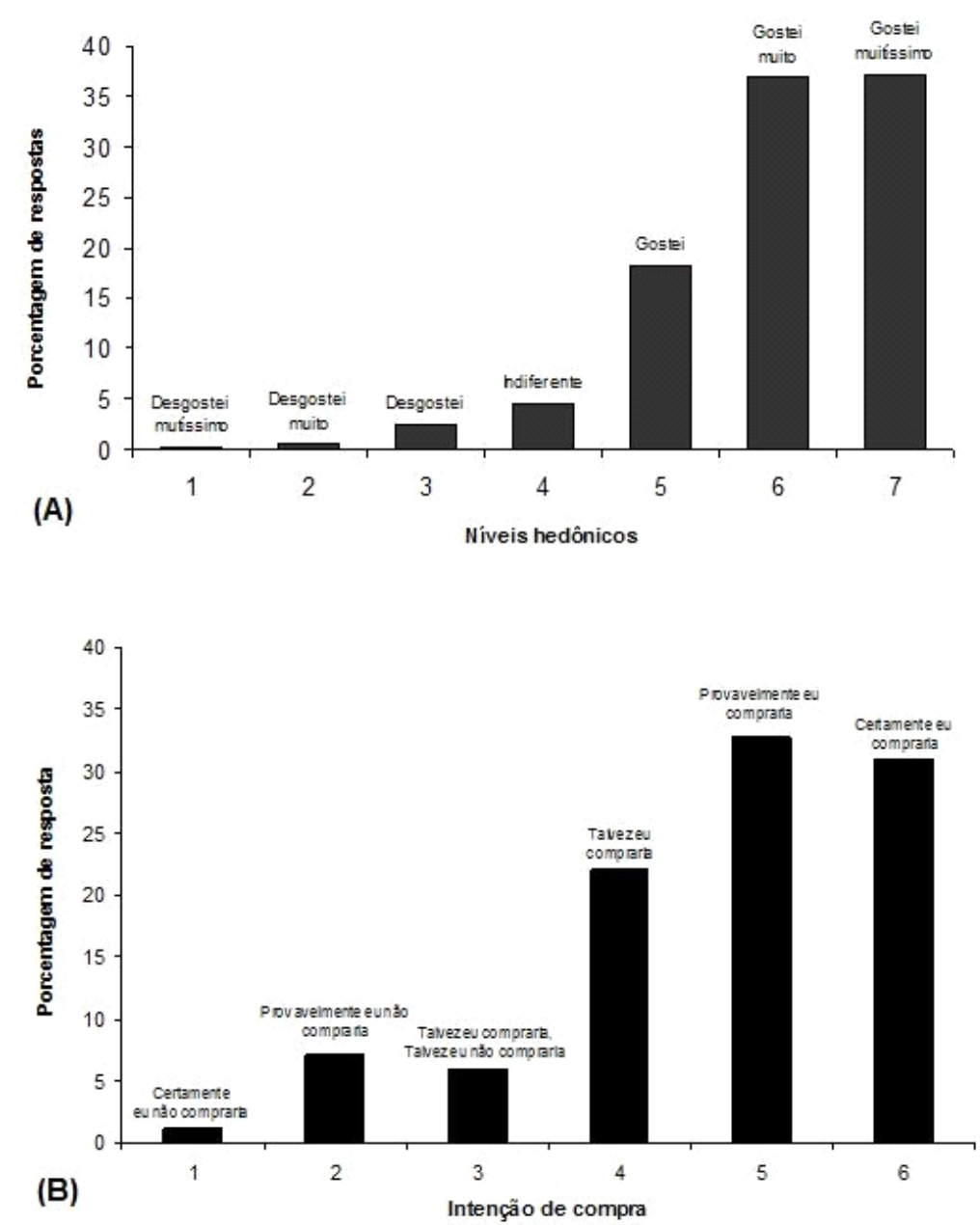

\footnotetext{
FIGURA 6 - DISTRIBUIÇÃO DAS PORCENTAGENS DE VALORES ATRIBUÍDOS AO FERMENTADO FRISANTE DE MAÇÃ PARA ACEITABILIDADE (A) E FREQUÊNCIA DAS CATEGORIAS DE INTENÇÃO DE COMPRA PARA O PRODUTO DESENVOLVIDO (B)
} 


\section{CONCLUSÃO}

O fermentado de maçã diluído para $4,5^{\circ} \mathrm{GL}$ foi corrigido com suco crioconcentrado para $50 \mathrm{~g} \cdot \mathrm{L}^{-1}$ de açúcares totais. Essa correção aumentou o teor de compostos fenólicos e a atividade antioxidante, que permaneceram semelhantes ao do suco antes da fermentação. A mistura do crioconcentrado com o fermentado proporcionou aroma frutado à bebida, intensificado pelo gás carbônico. A acidez, corrigida para 0,75 g.100 mL-1 semelhante à de maçãs ácidas na França, proporcionou equilíbrio entre acidez e açúcares. A espuma, próximo ao natural, porém mais persistente, foi conseguida com a adição de alginato na proporção de $4,0 \mathrm{~g} \cdot \mathrm{hL}^{-1}$. A amostra preferida no teste de ordenação foi a que continha 50 g.L.-1 de açúcares e $0,75 \mathrm{~g} .100 \mathrm{~mL}^{-1}$ de acidez. Na avaliação da aceitabilidade obteve-se índice de $81,63 \%$ e intenção de compra de aproximadamente $85 \%$, indicando que o produto apresenta potencial tecnológico para comercialização. As principais características atribuídas ao produto pelos consumidores foram a boa aparência, a presença de espuma, o sabor e a baixa graduação alcoólica. Desta forma, foi possível elaborar fermentado frisante de maçã semelhante à sidra francesa a partir de maçã de mesa (Gala), demonstrando a possibilidade de se fabricar produto com qualidade mediante adaptações de tecnologia, conhecimento dos padrões de identidade do produto europeu e preferências do consumidor brasileiro.

\section{ABSTRACT}

\section{ELABORATION OF A SPARKLING APPLE WINE WITH CHARACTERISTICS SIMILAR TO THE FRENCH CIDER}

In this paper the objective was to elaborate a fermented sparkling beverage with apple based on the French cider standard of quality and on the Brazilian consumer preference. The depectinized Gala juice was used for crio-concentration as well as for fermentation. Alcoholic degree was normalized to $4.5^{\circ} \mathrm{GL}$, sugar and acidity were adjusted with crioconcentrate and citric acid respectively according to the sequential order test. Foam was achieved after tests with propyl glycol alginate. Residual sugar content after correction using crioconcentrate juice was of $50 \mathrm{~g} \cdot \mathrm{L}^{-1}$, increasing its phenolic compounds and antioxidant activity. Acidity was adjusted to $0.75 \mathrm{~g} .100 \mathrm{~mL}^{-1}$ becoming similar to the French cider acidity. Foam more stable than the natural was reached with the utilization of propylen glycol alginate at a proportion of $4.0 \mathrm{~g} \cdot \mathrm{hL}^{-1}$. The acceptance of the product was of $81.63 \%$ and intention of purchase was of approximately $85 \%$, indicating that the product attend to the consumers preference. In this manner was elaborated a beverage with characteristics of the French cider that was well accepted by consumers showing a market potential.

KEY-WORDS: CRYOCONCENTRATE; APPLE WINE; PHENOL; ANTIOXIDANT ACTIVITY; SENSORY ANALYSIS.

\section{REFERÊNCIAS}

1 ABNT. Associação Brasileira de Normas Técnicas. NBR 14.141: escalas utilizadas em análise sensorial dos alimentos e bebidas - testes de aceitabilidade. São Paulo, 1998. 8 p.

2 ABNT. Associação Brasileira de Normas Técnicas. NBR 13.170: teste de ordenação em análise sensorial. São Paulo, 1994. $7 \mathrm{p}$

3 ANDRES-LACUEVA, C.; GALLART, M.; LÓPEZ-TAMAMES, E.; LAMUELA-RAVENTÓS, R.M. Influence of variety and aging on foaming properties of sparkling wine (Cava). I. J. Agric. Food Chem., v. 44, n. 12, p. 3826-3829, 1996.

4 ANDRES-LACUEVA, C.; LAMUELA-RAVENTÓS, R.M.; BUXADERAS, S.; DE LA TORRE BORONAT, M.C. Influence of variety and aging on foaming properties of Cava (sparkling wine). II. J. Agric. Food Chem., v. 45, n.7, p. 2520-2525, 1997.

5 BEECH, F. English cidermaking: technology, microbiology and biochemistry. Progress in Industrial Microbiology, v.11, p.133-213, 1972.

6 BENZIE, I.F.F.; STRAIN, J.J. The ferric reducing ability of plasma (FRAP) as a measure of "antioxidant power": the FRAP assay. Analytical Biochemistry, v. 239, n. 1, p. 70-76, 1996. 
7 BLANCO-GOMIS, D.; MANGAS-ALONSO, J.J.; JUNCO-CORUJEDO, S.; GUTIERREZ-ALVAREZ, M.D. Cider proteins and foam characteristics: a contribution to their characterization. Journal of Agricultural and Food Chemistry, v.55, n.7, p.2526-2531, 2007.

8 BRASIL. Ministério da Agricultura, Pecuária e Abastecimento. Decreto n ${ }^{\circ} 6.871$, de 4 de junho de 2009. Regulamenta a Lei ํo 8.918, de 14 de julho de 1994, que dispõe sobre a padronização, a classificação, o registro, a inspeção, a produção e a fiscalização de bebidas. Diário Oficial [da] República Federativa do Brasil, Brasília, DF, 4 de junho de 2009

9 CHAVARRIA, G.; SANTOS, H.P.S.; ZANUS, M.C.; ZORZAN, C.; MARODIN, G.A.B. Caracterização físico-química do mosto e do vinho Moscato Giallo em videiras cultivadas sob cobertura de plástico. Pesq. Agropec. Bras., v.43, n.7, p.911-916, 2008.

10 CLIFF, M.; DEVER, M.C.; GAYTON, R. Juice extraction process and apple cultivar influences on juice properties. Journal of Food Science, v.56, n.6, p.1614-1627, 1991.

11 DRILLEAU, J.F. Consolider les connaissances et maîtriser la qualité du produit fini. Revue Pomme à Cidre, n.23, p.23-25, 1991.

12 EPAGRI. Empresa de Pesquisa Agropecuária e Extensão Rural de Santa Catarina. A cultura da macieira. Florianópolis, 2002. $743 \mathrm{p}$.

13 FARIA, E.V.; YOTSUYANAGI, K. Técnicas de análise sensorial. Campinas: Ital/Lafise, 2002. 116 p.

14 FERREIRA, P. Yes, nós temos maçãs. Inovação em Pauta, n. 5, p.43-47, fev./mar., 2009.

15 FERREIRA, V.L.; ALMEIDA, T.C.A.; PETTINELLI, M.L.C.V.; DA SILVA, M.A.A.P.; CHAVES, J.B.P.; BARBOSA, E.M.M. Testes afetivos. In: ANÁLISE sensorial - testes discriminativos e afetivos. Campinas: Profíqua, 2000, p. 54-71.

16 FELLOWS, P.J. Tecnologia do processamento de alimentos: princípios e práticas. 2. ed. Porto Alegre: Artmed, 2006. $602 \mathrm{p}$.

17 GALLART, M.; TOMÁS, X.; SUBERBIOLA, G.; LÓPEZ-TAMAMES, E.; BUXADERAS, S. Relationship between foam parameters obtained by the gas-sparging method and sensory evaluation of sparkling wines. J. Sci. Food Agric., v. 84, n.2, p.127-133, 2004.

18 GIRBAU-SOLA, T.; LOPEZ-BARAJAS, M.; LOPEZ-TAMAMES, E.; BUXADERAS, S. Foam aptitude of trepat and monastrell red varieties in Cava elaboration. 2. Second fermentation and aging. Journal of Agricultural and Food Chemistry, v.50, n.20, p.5600-5604, 2002.

19 GOSSÉ, F.; GUYOT, S.; ROUSSI, S.; LOBSTEIN, A.; FISCHER, B.; SEILER, N.; RAUL, F. Chemopreventive properties of apple procyanidins on human colon cancer-derived metastatic SW620 cells and in a rat model of colon carcinogenesis. Carcinogenesis, v.26, n.7, p.1291-1295, 2005.

20 IAL. Instituto Adolfo Lutz. Métodos físicos e químicos para análise de alimentos. In: Instituto Adolfo Lutz. 5. ed. São Paulo, 2008.

Normas analíticas do

21 JULIEN, A.; TRIOLI, G.; DULAU, L. Maîtrise de la fermentation alcoolique: les facteurs de croissance de la levure et la prévention des arrêts. Partie 2: Gestion de la fermentation alcoolique et prévention des arrêts de fermentation. Revue des Enologues, n.101, p.25-29, 2001.

22 LEA, A.G.; ARNOLD, G.M. The phenolics of ciders: bitterness and astringency. Journal of the Science of Food and Agriculture, v.29, n. 5, p.478-483, 1978.

23 LEA, A.; DRILLEAU, J.F. Cidermaking. In: LEA, A.G.H.; PIGGOTT, J.R. (Eds.) Fermented beverage production. $2^{\text {nd }}$ ed. New York: Klumer Academic/Plenum Publishers, 2003. p.59-87.

24 LEE, C.Y.; SMITH, N.L. Apples: an important source of antioxidants in the American diet. New York Fruit Quarterly, v.8, n.2, p.15-17, 2000.

25 LEE, S.S.; ROBINSON, F.M.; WANG, H.Y. Rapid determination of yeast viability. Biotechnology and Bioengineering Symposium, n.11, p.641-649, 1981.

26 LIGER-BELAIR, G.; MARCHAL, R.; ROBILLARD, B.; VIGNES-ADLER, M.; MAUJEAN, A.; JEANDET, P. Study of effervescence in a glass of champagne: frequencies of bubble formation, growth rates, and velocities of rising bubbles. Am. J. Enol. Vitic., v. 50, n. 3, 1999, p.317-323, 1999.

27 LIGER-BELAIR, G.; LEMARESQUIER, H.; ROBILLARD, B.; DUTEURTRE, B.; JEANDET, P. The secrets of fizz in champagne wines: a phenomenological study. Am. J. Enol. Vitic., v.52, n.2, p.88-92, 2001.

28 LÓPEZ-BARAJAS, M.; LÓPEZ-TAMAMES, E.; BUXADERAS, S.; DE LA TORRE BORONAT, M.C. Effect of vinification and variety on foam capacity of wine. Am. J. Enol. Vitic., v. 49, p. 397-402, 1998. 
29 MANGAS, J.J.; RODRIGUEZ, R.; SUAREZ, B.; PICINELLI, A.; DAPENA, E. Study of the phenolic profile of cider apple cultivar at maturity by multivariate techniques. Journal of Agricultural and Food Chemistry, v.47, n.10, p.40464052, 1999.

30 MORENO-ARRIBAS, V.; PUEYO, E.; NIETO, F.J.; MARTIN, A.; LVAREZ, P.J.; POLO, M.C. Influence of the polysaccharides and the nitrogen compounds on foaming properties of sparkling wines. Food Chem., v. 70, p. 309-317, 2000.

31 NOGUEIRA, A.; WOSIACKI, G. Sidra. In: VENTURINI FILHO, W. G. (Org.). Bebidas alcoólicas: ciência e tecnologia. São Paulo: Edgard Blücher, 2010. v.1, p. 113-142.

32 NOGUEIRA, A.; MONGRUEL, C.N.; SIMÕES, D.R.S.; WASZCZYNSKYJ, N.; WOSIACKI, G. Effect of biomass reduction on the fermentation of cider. Brazilian Archives of Biology and Technology, v.50, n.6, p.10891098, 2007.

33 NOGUEIRA, A.; QUÉRÉ, J.M.L.; GESTIN, P.; MICHEL, A.; WOSIACKI, G.; DRILLEAU, J.F. Slow fermentation in French cider processing due to partial biomass reduction. J. Inst. Brew., v.114, n.2, p.102-110, 2008.

34 NOGUEIRA, A.; QUÉRÉ, J. M. L.; BULDIN, R. Oxygène et stabilité des cidres. Revue Pomme à Cidre, v. 5, p.16-17, 2003.

35 PAGANINI, C.; NOGUEIRA, A.; DENARDI, F.; WOSIACKI, G. Aptidão industrial de seis cultivares de maçã (dados da safra 2001/2002). Ciência e Agrotecnologia, v.28, n.6, p.1336-1343, 2004.

36 PUEYO, E.; MARTIN-ALVAREZ, P.J.; POLO, M.C. Relationship between foam characteristics and chemical composition in wines and Cavas (sparklingwines). Am. J. Enol.Vitic., v.46, p.518-524, 1995.

37 PULIDO, R.; BRAVO, L.; SAURA-CALIXTO, F. Antioxidant activity of dietary polyphenols as determined by a modified ferric reducing/antioxidant power assay. Journal of Agricultural and Food Chemistry, v. 48, n. 8, p.3396-3402, 2000.

38 QUEIROZ, M.I.; TREPTOW, R.O. Análise sensorial para a avaliação da qualidade dos alimentos. Rio Grande: Editora da Furg, 2006.

39 ROGER, J.M.; SABLAYROLLES, J.M.; STEYER, J.P.; BELLON-MAUREL, V. Pattern analysis techniques to process fermentation curves: application to discrimination of enological alcoholic fermentations. Biotechnol. Bioeng., v.79, n.7, p.804-815, 2002.

40 SEERAM, N.P.; NAIR, M.G. Inhibition of lipid peroxidation and structure activity related studies of the dietary constituents anthocyanins, anthocyanidins and catechins. Journal of Agricultural and Food Chemistry, v.50, p.5308-5312, 2002.

41 SHAHIDI, F.; NACZK, M. Food phenolics: sources, chemistry, effect, applications. Pennsylvania: Technomic, 1995. $321 \mathrm{p}$.

42 SILVA, M.A.A.P. Métodos de avaliação sensorial de alimentos. Campinas: Escola de Extensão UNICAMP, 1997, 71 p. (Apostila).

43 SINGLETON, V.; ROSSI, J.A. Colorimetry of total phenolics with phosphomolybdic-phosphotungstic acid reagents. American Journal of Enology and Viticulture, v. 16, n. 3, p. 144-158, 1965

44 SLUIS, A.A. Van der; DEKKER, M.; JONGEN, W.M.F.; SKREDE, G. Activity and concentration of polyphenolic antioxidants in apple juice. I. Effect of existing production methods. Journal of Agricultural and Food Chemistry, v.50, n.25, p.7211-7219, 2002

45 TANNER, H.; BRUNNER, H.R. Getränke anlytik: untersuchungsmethode für dia labor und betriebspraxis. Schwäbische Hall: Ulmer Verlas, 1985. 206 p.

46 WIECHETECK, F.V.B.; NOGUEIRA, A.; DRILLEAU, J.F.; WOSIACKI, G. Efeito da crioconcentração sobre o teor de compostos fenólicos em mostos industriais de maçãs. Publicatio UEPG. Ciências Exatas e da Terra, Ciências Agrárias e Engenharias, v.11, n.1, p.27-34, 2005.

47 WOSIACKI, G.; NAMIUCHI, N.N.; CERIBELLI, M.I.P.F.; SATAQUE, E.Y.; SICHIERI, V.L.F.S.; OLIVEIRA, T.C.R.M.; OLIVEIRA, C.E. Estabilidade do suco clarificado de maçã. Parte I - Processo de obtenção do suco de maçã. Brazilian Archives of Biology and Technology, v. 32, n.4, p. 775-786, 1989.

48 WOSIACKI, G.; NOGUEIRA, A.; SILVA, N.C.; DENARDI, F.; VIEIRA, R.G. Quality profile of samples of 139 apples cultivars harvested in Brazil from 1982 to 2006. Acta Alimentaria, v.37, n.1, p.9-22, 2008.

49 WOSIACKI, G.; NOGUEIRA, A. Suco de maçã. In: VENTURINI FILHO, W.G. (Org.). Bebidas não-alcoólicas: ciência e tecnologia. São Paulo: Edgard Blücher, 2010. v. 2, p.269-302. 
50 ZARDO, D.M.; ALBERTI, A.; DANTAS, A.P.C.; GUYOT, S.; WOSIACKI, G.; NOGUEIRA, A. Efeito do processamento no teor de compostos fenólicos e na atividade antioxidante em fermentados de maçã. Semina. Ciências Agrárias, v.29, p.829-838, 2008.

\section{AGRADECIMENTOS}

Os autores agradecem à Universidade Estadual de Ponta Grossa por ceder os laboratórios para a realização deste trabalho, bem como ao CNPq pela concessão de bolsas que subsidiaram o trabalho dos pesquisadores, e ao Grupo de Trabalho sobre Maçã - GTM (www.uepg.br/gtm) pelo apoio complementar. 